\title{
Teste de envelhecimento acelerado em sementes de crambe (Crambe abyssinica Hochst), cultivar FMS Brilhante
}

\author{
Hugo Tiago Ribeiro Amaro', Andréia Márcia Santos de Souza David², Izabel Costa Silva Neta ${ }^{3}$. Miquéias de \\ Oliveira Assis ${ }^{4}$ Eduardo Fontes Araújo ${ }^{5}$, Roberto Fontes Araújo 6
}

\begin{abstract}
RESUMO
A utilização de sementes de alta qualidade fisiológica merece destaque na instalação de qualquer cultura, sendo necessário avaliá-las por meio dos testes de germinação e de vigor. O objetivo deste trabalho foi avaliar a eficiência do teste de envelhecimento acelerado na determinação do vigor de sementes de crambe. Foram utilizados cinco lotes de sementes de crambe, cultivar FMS Brilhante, e a qualidade inicial de cada lote foi avaliada pela determinação do teor de água, germinação, primeira contagem de germinação, emergência de plântulas e índice de velocidade de emergência. Para o teste de envelhecimento acelerado, as sementes foram submetidas a temperaturas de 41 e $43^{\circ} \mathrm{C}$, em câmara tipo BOD, durante 48, 72 e 96 horas. No final de cada período de envelhecimento, as sementes foram colocadas para germinar, conforme método descrito para o teste de germinação. O delineamento experimental foi inteiramente casualizado, com quatro repetições por lote. $\mathrm{O}$ teste de envelhecimento acelerado na condição de $41^{\circ} \mathrm{C}$, por $72 \mathrm{~h}$, proporciona maior diferenciação do vigor entre os lotes de sementes de crambe, cultivar FMS Brilhante.
\end{abstract}

Palavras-chave: Crambe abyssinica Hochst, oleaginosa, desempenho fisiológico, vigor.

\section{ABSTRACT \\ Accelerated aging test in seeds of crambe (Crambe abyssinica Hochst), cultivar FMS Brilhante}

The use of high physiological quality seeds is essential in the establishment of any crop. Germination and vigor tests are required for seed quality control. The objective of this study was to evaluate the efficiency of the accelerated aging test in determining the vigor of crambe seeds. The initial quality of five lots of crambe seeds, cultivar FMS Brilhante, was assessed by determining the water content, germination, germination first count, seedling emergence index and emergence rate. For the accelerated aging test, the seeds were subjected to temperatures of 41 and $43{ }^{\circ} \mathrm{C}$ in a BOD chamber for 48, 72 and 96 hours. At the end of each aging period, the seeds were put to germinate according to the methodology for the germination test. The experiment was arranged in a completely randomized design with four replications per lot. The accelerated aging test under the condition of $41{ }^{\circ} \mathrm{C}$ for $72 \mathrm{~h}$ provided the greatest vigor discrimination between the lots of crambe seeds, cultivar FMS Brilhante.

Key words: Crambe abyssinica Hochst, oilseed, physiological quality, force.

Recebido para publicação em 10/01/2012 e aprovado em 15/07/2013.

'Engenheiro-Agrônomo, Mestre. Departamento de Fitotecnia, Universidade Federal de Viçosa, Campus Viçosa, Avenida Peter Henry Rolfs, s/n, 36570-900, Viçosa, Minas Gerais, Brasil. htiagoamaro@yahoo.com.br (autor para correspondência).

2Engenheira-Agrônoma, Doutora. Departamento de Ciências Agrárias, Universidade Estadual de Montes Claros, Campus Janaúba, Avenida Reinaldo Viana, 2630, Bico da Pedra, Caixa Postal 91, 39440-000, Janaúba, Minas Gerais, Brasil. andreia.david@unimontes.br

3Engenheira-Agrônoma, Mestre. Departamento de Agricultura, Universidade Federal de Lavras, Campus Universitário, 37200-000, Lavras, Minas Gerais, Brasil. izabel_agronomia@hotmail.com

4Graduando em Agronomia. Departamento de Ciências Agrárias, Universidade Estadual de Montes Claros, Campus Janaúba, Avenida Reinaldo Viana, 2630, Bico da Pedra, Caixa Postal 91, 39440-000, Janaúba, Minas Gerais, Brasil. mick_eafsal@ @otmail.com

5Engenheiro-Agrônomo, Doutor. Departamento de Fitotecnia, Universidade Federal de Viçosa, Campus Viçosa, Avenida Peter Henry Rolfs, s/n, 36570-900, Viçosa, Minas Gerais, Brasil.efaraujo@ufv.br

6Engenheiro-Agrônomo, Doutor. Empresa de Pesquisa Agropecuária de Minas Gerais - EPAMIG, Vila Gianetti, Caixa Postal 216, 36571-000, Viçosa, Minas Gerais, Brasil. roberto.araujo@epamig.br

Rev. Ceres, Viçosa, v. 61, n.2, p. 202-208, mar/abr, 2014 


\section{INTRODUÇÃO}

Na produção de biodiesel, empresas e órgãos estaduais e federais vêm priorizando a busca por matériasprimas alternativas, sempre avaliando seus atributos sob aspectos agronômicos e tecnológicos, como: teor de óleo, produtividade, sistema produtivo e ciclo da cultura. Considerando-se esses aspectos, acredita-se que o Crambe abysinica Hochst, por ser também cultura de inverno, tem grande potencial para constituir-se em matéria-prima para o biodiesel, além de ser utilizado na rotação de culturas. Segundo Pitol (2008), a cultura do crambe apresenta tolerância à seca, principalmente a partir do seu desenvolvimento vegetativo, e a temperaturas amenas, comportando-se como cultura de outono/ inverno.

Cultivada em maior escala no México e nos Estados Unidos para produção de óleo industrial, o seu cultivo iniciou-se, no Brasil, em 1995, na Fundação MS, no município de Maracaju - MS. Porém, na época, a planta era estudada somente para fins de rotação de cultura (Echevenguá, citado por Jasper et al., 2010). Pertencente à família Brassicaceae, o crambe é cultura de ciclo anual, cujas sementes contêm cerca de 35 a $60 \%$ de óleo. É planta nativa do Mediterrâneo e cultivada em algumas regiões tropicais e subtropicais (Carneiro et al., 2009).

A utilização de sementes de alta qualidade constitui a base para elevação da produtividade agrícola. Os atributos da qualidade fisiológica das sementes têm sido objeto de inúmeras pesquisas, em decorrência de as sementes estarem sujeitas a inúmeras mudanças degenerativas após a sua maturidade (Freitas \& Nascimento, 2006). Para avaliar a qualidade fisiológica de lotes de sementes, adotamse os testes de germinação e de vigor (Flavio \& Paula, 2010).

A qualidade fisiológica da semente é avaliada, rotineiramente, pelo teste de germinação que, conduzido sob condições ótimas de ambiente, fornece o potencial máximo de germinação, estabelecendo o limite para o desempenho do lote após a sua semeadura (Brasil, 2009). Entretanto, em razão de suas limitações, principalmente quanto à menor sensibilidade para a diferenciação da qualidade e à frequente discrepância dos resultados com a emergência das plântulas em campo, são necessários também os resultados obtidos nos testes de vigor. Nestes, busca-se obter respostas complementares às fornecidas pelo teste de germinação, possibilitando a obtenção de informações consistentes (Ohlson et al., 2010).

Para determinação do vigor das sementes, existem vários testes, cujo objetivo é identificar diferenças importantes no potencial fisiológico de lotes de sementes, especialmente daqueles que apresentam poder germinativo semelhante.
Entre os testes de vigor úteis aos trabalhos de pesquisa na área de tecnologia de sementes, o teste de envelhecimento acelerado tem sido um dos mais utilizados. Sua metodologia já foi ajustada para diversas espécies, porém, para algumas, como o crambe, ainda não está aprimorada, não existindo consenso entre os pesquisadores quanto às condições mais adequadas de temperatura e período de exposição para sua execução.

Ressalte-se, portanto, que os resultados desse teste devem permitir a classificação dos lotes em diferentes níveis de vigor, representando um auxílio muito importante para a tomada de decisões, pelas empresas produtoras de sementes, quanto à comercialização dos lotes, direcionando-os para locais em que poderiam apresentar maior potencial de desempenho (Bittencourt \& Vieira, 2006).

No envelhecimento acelerado, as sementes são submetidas a temperaturas e umidades relativas elevadas, por períodos relativamente curtos; em seguida, são colocadas para germinar. Lotes de sementes de alto vigor devem manter sua viabilidade quando submetidos a essas condições, enquanto os de baixo vigor terão sua viabilidade reduzida (AOSA, 1983). O teste de envelhecimento acelerado foi, originalmente, desenvolvido para determinar o potencial de armazenamento das sementes. No entanto, além de estudos com esse objetivo, também têm sido realizados trabalhos para verificar sua eficiência na avaliação do potencial de emergência das plântulas em campo (Freitas \& Nascimento, 2006).

Vários fatores afetam o comportamento das sementes submetidas ao teste, sendo o binômio temperatura e período de envelhecimento o mais estudado. O teste de envelhecimento acelerado pode ser conduzido com temperaturas entre 41 e $45^{\circ} \mathrm{C}$, sendo que, mais recentemente, a maioria dos trabalhos indica o uso de $41^{\circ} \mathrm{C}$ (Marcos Filho, 1999a).

Quanto à cultura do crambe, ainda são escassos os estudos sobre avaliação da qualidade fisiológica de suas sementes. Por essa razão, baseando-se na eficiência do teste de envelhecimento acelerado para outras espécies, este trabalho objetivou ajustar a sua metodologia para sementes de crambe, possibilitando identificar com segurança os níveis de vigor dos lotes.

\section{MATERIAL E MÉTODOS}

O experimento foi conduzido no Laboratório de Análise de Sementes, do Departamento de Ciências Agrárias, Universidade Estadual de Montes Claros - UNIMONTES, Campus Janaúba-MG, de fevereiro a abril de 2011. Foram utilizadas sementes de crambe, cultivar FMS Brilhante, safra 2010, provenientes da COOAPI (Cooperativa Agropecuária Pioneira), localizada na região da Chapada Gaúcha-MG. 
Após a recepção das sementes, elas foram separadas em amostras e armazenadas, por seis meses, em diferentes condições de ambiente e em embalagens de diferentes permeabilidades, consistindo nos seguintes tratamentos (lotes): sacos de papel + câmara fria a $10{ }^{\circ} \mathrm{C}$ e $65 \%$ de umidade relativa do ar (Lote 1); sacos de polietileno + câmara fria (Lote 2); sacos de papel + temperatura ambiente a $20^{\circ} \mathrm{C}$ (Lote 3$)$; sacos de polietileno + temperatura ambiente a $20^{\circ} \mathrm{C}$ (Lote 4 ) e sacos de polietileno + temperatura ambiente a $25^{\circ} \mathrm{C}$ (Lote 5). Em seguida, as avaliações da qualidade fisiológica das sementes foram realizadas por meio dos seguintes testes:

a) Teor de água - determinado antes e após o envelhecimento acelerado, pelo método da estufa, a $105{ }^{ \pm} 3{ }^{\circ} \mathrm{C}$, durante 24 horas, utilizando-se três repetições de $3 \mathrm{~g}$ de sementes para cada lote, sendo os resultados expressos em percentagem, conforme método prescrito nas Regras para Análise de Sementes (Brasil, 2009).

b) Teste de germinação - realizado com quatro repetições de 50 sementes para cada lote, utilizando-se o papel mata-borrão e caixas plásticas transparentes com tampa (gerbox), onde as sementes foram distribuídas sobre uma folha de papel mata-borrão, umedecida com água destilada, utilizando-se volume equivalente a 2,5 vezes o peso do papel. As caixas foram colocadas em germinador, previamente regulado à temperatura constante de $25^{\circ} \mathrm{C}$. As avaliações foram realizadas no quarto e sétimo dias após a semeadura e os resultados expressos em percentagem, segundo os critérios estabelecidos pelas Regras para Análise de Sementes (Brasil, 2009).

c) Primeira contagem do teste de germinação - realizada simultaneamente com o teste de germinação, considerando-se a percentagem de plântulas normais obtidas no quarto dia após a semeadura (Brasil, 2009).

d) Emergência de plântulas - conduzida sob condições ambientais controladas de laboratório, utilizando-se areia lavada e esterilizada, em estufa, a $200{ }^{\circ} \mathrm{C}$, durante duas horas. As sementes foram semeadas a $2 \mathrm{~cm}$ de profundidade em caixas tipo gerbox e o teor de água foi mantido com irrigações leves diariamente (Brasil, 2009). Utilizaram-se quatro repetições de 50 sementes por lote e os resultados foram obtidos pelo número de plântulas emersas, determinado por ocasião do sétimo dia após a montagem do experimento.

e) Índice de velocidade de emergência - conduzido em conjunto com o teste de emergência de plântulas, anotando-se, diariamente, no mesmo horário, o número de plântulas emersas, até a estabilização da emergência. Ao final do teste, com os dados diários do número de plântulas emergidas, foi calculado o índice de velocidade de emergência, empregando-se a fórmula proposta por Maguire (1962). f) Envelhecimento acelerado (método tradicional) - utilizou-se o método proposto por Marcos Filho (1999a), colocando-se, aproximadamente, 300 sementes de cada amostra em uma câmara de envelhecimento acelerado. As sementes foram distribuídas em camada única sobre tela de alumínio, acoplada ao interior da caixa plástica tipo gerbox, contendo, no fundo, $40 \mathrm{~mL}$ de água destilada. Em seguida, as caixas foram tampadas e transferidas para uma incubadora tipo BOD, a 41 e $43^{\circ} \mathrm{C}$, onde permaneceram durante 48, 72 e 96 horas. No final de cada período, as sementes foram postas para germinar nas mesmas condições descritas anteriormente para o teste de germinação, sendo o número de plântulas normais registrado no quarto dia após a semeadura e os resultados expressos em percentagem.

O delineamento experimental utilizado foi o inteiramente casualizado, com quatro repetições por tratamento. Os dados foram submetidos aos testes de normalidade e de homogeneidade de variância, que indicaram a não necessidade de transformação. Em seguida, os resultados foram submetidos à análise de variância e as características com variação significativa, a 5\% de probabilidade, em resposta aos tratamentos, foram submetidas ao teste ScottKnott, também a 5\% de probabilidade.

Foram calculados os coeficientes de correlação de Pearson (r) entre o teste de envelhecimento acelerado e os demais testes utilizados, para avaliar-se a qualidade fisiológica inicial das sementes. A significância dos valores de $\mathrm{r}$ foi determinada pelo teste $\mathrm{t}$, a $5 \%$ de probabilidade. Os dados referentes ao grau de umidade das sementes não foram submetidos à análise estatística.

\section{RESULTADOS E DISCUSSÃO}

Os resultados dos testes de germinação indicam que não houve diferença significativa na percentagem de plântulas normais, entre os lotes estudados (Tabela 1), justificando, assim, a necessidade de utilização de testes de vigor para obtenção de informações mais conclusivas. Vale ressaltar que a utilização apenas do teste de germinação pode não fornecer resultados seguros, quanto à qualidade fisiológica dos lotes avaliados. Segundo Marcos Filho (1999b), uma das finalidades dos testes de vigor é revelar diferenças na qualidade fisiológica das sementes, que não são detectadas no teste de germinação.

No entanto, observa-se que os resultados do teste de vigor, pela primeira contagem de germinação, proporcionaram informações semelhantes às do teste de germinação. Isso sugere baixa sensibilidade desse teste de vigor, além da já proporcionada pelo teste de germinação, para a separação, em diferentes níveis de qualidade fisiológica, dos diferentes lotes estudados. Nesse sentido, Marcos Filho (1999b) ressalta também a importância da utilização 
de mais de um teste, para se determinar o vigor das sementes, em função da variação da eficiência dos procedimentos disponíveis.

Embora o teste de germinação possa fornecer informações sobre o desempenho das sementes, e a primeira contagem da germinação possa ser considerada indicativa de vigor, sabe-se que a germinação e a redução da velocidade de germinação não estão entre os eventos iniciais do processo de deterioração de sementes (Delouche \& Baskin, 1973), justificando a necessidade da realização de um número maior de testes.

Avaliando-se o vigor das sementes pelo teste de emergência de plântulas, verificou-se que houve diferença significativa entre os lotes estudados (Tabela 1). Pelos resultados do teste, os lotes 2, 4 e 5 foram classificados como os de melhor qualidade, sendo os lotes 1 e 3 os de pior qualidade.

Observa-se, também, que os resultados obtidos na determinação do índice de velocidade de emergência (Tabela 1) foram semelhantes aos obtidos nos testes de germinação e primeira contagem, não sendo eficientes para a separação dos lotes de sementes de crambe em diferentes níveis de vigor.

Somente um dos testes realizados para avaliação da qualidade fisiológica inicial dos lotes de sementes de crambe permitiu diferenciá-los, ainda assim, em apenas dois níveis de vigor, além de apresentar resultados confrontantes com os dos testes de vigor utilizados, reforçando, assim, a necessidade de realização de um maior número de testes que permitam potencializar a classificação segura dos lotes em diferentes níveis de vigor, o que pode representar riscos em tomadas de decisões quanto à utilização desses lotes.

Costa et al. (2008) verificaram que os testes de primeira contagem de germinação e de emergência de plântulas

Tabela 1. Germinação $(G)$, primeira contagem do teste de germinação (PCG), emergência de plântulas (EP) e índice de velocidade de emergência (IVE) de cinco lotes de sementes de crambe

\begin{tabular}{lllll}
\hline Lote & $\mathbf{G}(\boldsymbol{\%})$ & $\mathbf{P C G}(\%)$ & $\mathbf{E P}(\%)$ & $\mathbf{I V E}$ \\
\hline 1 & $54 \mathrm{~A}$ & $29 \mathrm{~A}$ & $52 \mathrm{~B}$ & $10,0 \mathrm{~A}$ \\
2 & $39 \mathrm{~A}$ & $19 \mathrm{~A}$ & $64 \mathrm{~A}$ & $9,7 \mathrm{~A}$ \\
3 & $39 \mathrm{~A}$ & $19 \mathrm{~A}$ & $50 \mathrm{~B}$ & $9,1 \mathrm{~A}$ \\
4 & $33 \mathrm{~A}$ & $12 \mathrm{~A}$ & $70 \mathrm{~A}$ & $9,6 \mathrm{~A}$ \\
5 & $44 \mathrm{~A}$ & $21 \mathrm{~A}$ & $65 \mathrm{~A}$ & $10,0 \mathrm{~A}$ \\
Média & 42 & 19 & 60 & 9,7 \\
\hline Teste "F" & $0,616^{\text {ns }}$ & $0,845^{\text {ns }}$ & $6,574^{* *}$ & $0,305^{\text {ns }}$ \\
\hline CV $(\%)$ & 9,2 & 15,0 & 15,5 & 9,7
\end{tabular}

Médias com letras maiúsculas diferentes na mesma coluna diferem $(\mathrm{P}<0,05)$ pelo teste Scott-Knott

ns - Não significativo e, (**) Significativo a $5 \%$ de probabilidade pelo teste F. permitiram melhor classificação dos lotes, quanto ao seu potencial fisiológico, não claramente evidenciada pelo teste de germinação, quando realizado com repolho e couve-brócolis; já o índice de velocidade de emergência, por outro lado, não possibilitou a diferenciação dos lotes.

Nesse sentido, o teste de envelhecimento acelerado figura como teste capaz de proporcionar informações com alto grau de consistência, identificando lotes mais vigorosos, que, consequentemente, apresentam sementes com deterioração mais reduzida, mantendo a sua viabilidade durante o processo de armazenagem.

Na Tabela 2, encontram-se os teores de água inicial e após diferentes períodos de envelhecimento das sementes. Observa-se que as sementes dos diferentes lotes apresentaram teor de água médio inicial de 7,2\%. Inicialmente, houve uma variação de 6,5 a $8,0 \%$ no teor de água das sementes. A comparação de amostras que apresentam teor de água semelhantes antes do envelhecimento acelerado é conveniente, embora diferenças de até dois pontos percentuais não sejam comprometedoras (Marcos Filho, 1999a).

Coimbra et al. (2009) salientam que o teor de água inicial das sementes é um fator primordial para a padronização dos testes de avaliação de qualidade a serem realizados. $\mathrm{O}$ teor elevado de água pode favorecer o desempenho das sementes durante a realização das análises. No envelhecimento acelerado, se as sementes apresentarem teor de água inicial muito distinto, há uma variação acentuada na velocidade de umedecimento e, certamente, diferenças na intensidade de deterioração (Rocha et al., 2007).

Verifica-se, pela Tabela 2, que as sementes apresentaram acréscimos nos seus teores de água quando o período de envelhecimento aumentou de 48 para 72 horas, nas

Tabela 2. Teor de água (\%) inicial e após os períodos de envelhecimento acelerado, em duas temperaturas, de cinco lotes de sementes de crambe

\begin{tabular}{|c|c|c|c|c|}
\hline \multirow[t]{2}{*}{ Lote } & \multirow[t]{2}{*}{ Inicial } & \multicolumn{3}{|c|}{$\begin{array}{l}\text { Envelhecimento acelerado } \\
\left(41^{\circ} \mathrm{C}\right)\end{array}$} \\
\hline & & $48 \mathrm{~h}$ & $72 \mathrm{~h}$ & $96 \mathrm{~h}$ \\
\hline 1 & 6,5 & 25,8 & 27,8 & 24,0 \\
\hline 2 & 7,7 & 25,3 & 28,0 & 28,5 \\
\hline 3 & 6,5 & 25,0 & 29,0 & 32,0 \\
\hline 4 & 7,1 & 23,4 & 30,5 & 29,0 \\
\hline 5 & 8,0 & 27,9 & 29,4 & 28,0 \\
\hline \multirow[t]{2}{*}{ Lote } & \multirow[t]{2}{*}{ Inicial } & \multicolumn{3}{|c|}{$\begin{array}{c}\text { Envelhecimento acelerado } \\
\left(43^{\circ} \mathrm{C}\right)\end{array}$} \\
\hline & & $48 \mathrm{~h}$ & $72 \mathrm{~h}$ & $96 \mathrm{~h}$ \\
\hline 1 & 6,5 & 25,5 & 27,2 & 27,6 \\
\hline 2 & 7,7 & 27,5 & 29,8 & 29,7 \\
\hline 3 & 6,5 & 23,2 & 27,0 & 29,0 \\
\hline 4 & 7,1 & 26,8 & 29,7 & 29,4 \\
\hline 5 & 8,0 & 26,0 & 28,9 & 25,3 \\
\hline
\end{tabular}

Rev. Ceres, Viçosa, v. 61, n.2, p. 202-208, mar/abr, 2014 
duas temperaturas estudadas. Entretanto, houve pouca variação nos teores de água a partir de 72 horas de envelhecimento, possivelmente em função do maior aproveitamento da água absorvida pela semente em seus processos metabólicos, já nos períodos iniciais do envelhecimento.

Sementes pequenas, como as de crambe, absorvem água mais rapidamente, caracterizando a fase I do padrão trifásico de hidratação da semente e, após esse período, há pouca ou nenhuma absorção de água, pois as células das sementes não podem mais se expandir, verificandose, já a partir desse estádio, a ativação dos processos metabólicos requeridos para o crescimento do embrião e início do processo germinativo (Castro et al., 2004).

Os resultados de vigor, pelo teste de envelhecimento acelerado, são apresentados nas Tabelas 3 e 4 . Quando as sementes foram submetidas ao teste de envelhecimento acelerado, sob $41^{\circ} \mathrm{C}$, por 48 horas, e $43^{\circ} \mathrm{C}$, por 72 e 96 horas, não houve diferença na qualidade fisiológica dos lotes, indicando a não eficiência em classificar os lotes de sementes de crambe em diferentes níveis de vigor.

Entretanto, resultados significativos foram observados quando as sementes dos lotes estudados foram envelhecidas, a $41^{\circ} \mathrm{C}$, por 72 e 96 horas (Tabela 3), e a 43 ${ }^{\circ} \mathrm{C}$, por 48 horas (Tabela 4). Quando as sementes foram envelhecidas a $41^{\circ} \mathrm{C} / 72 \mathrm{~h}$, o lote 1 apresentou desempenho superior, sementes dos lotes 4 e 5 apresentaram resultados intermediários, e os lotes 2 e 3 apresentaram sementes de pior qualidade. Mendes et al. (2010) verificaram que o teste de envelhecimento acelerado, a $41^{\circ} \mathrm{C} / 72 \mathrm{~h}$, proporcionou resultados satisfatórios para avaliação do potencial fisiológico de lotes de sementes de mamona do cultivar Al-Guarany. Resultados semelhantes foram observados por Dutra \& Vieira (2004) para sementes de soja e Ávila et al. (2006), para sementes de rabanete.

Tabela 3. Germinação (\%) após os períodos do teste de envelhecimento acelerado a $41^{\circ} \mathrm{C}$, em cinco lotes de sementes de crambe

\begin{tabular}{lccc}
\hline Lote & $\mathbf{4 1}^{\mathbf{0}} \mathbf{C} \mathbf{4 8 h}$ & $\mathbf{4 1}^{\circ} \mathbf{C} / \mathbf{7 2 h}$ & $\mathbf{4 1}^{\circ} \mathbf{C} / \mathbf{9 6 h}$ \\
\hline 1 & $42 \mathrm{~A}$ & $47 \mathrm{~A}$ & $30 \mathrm{~A}$ \\
2 & $29 \mathrm{~A}$ & $19 \mathrm{C}$ & $15 \mathrm{~B}$ \\
3 & $31 \mathrm{~A}$ & $16 \mathrm{C}$ & $16 \mathrm{~B}$ \\
4 & $31 \mathrm{~A}$ & $39 \mathrm{~B}$ & $17 \mathrm{~B}$ \\
5 & $39 \mathrm{~A}$ & $38 \mathrm{~B}$ & $9 \mathrm{~B}$ \\
\hline Média & 34 & 32 & 17 \\
\hline Teste "F" & $2,780^{\text {ns }}$ & $23,703^{* *}$ & $1,738^{*}$ \\
\hline CV $(\%)$ & 9,2 & 15,0 & 15,5 \\
\hline
\end{tabular}

Médias com letras maiúsculas diferentes na mesma coluna diferem $(\mathrm{P}<0,05)$ pelo teste Scott-Knott.

ns - Não significativo pelo teste $\mathrm{F}$ a $5 \%$ de probabilidade.

(*) e (**) Significativo a 5 e a $1 \%$ de probabilidade, pelo teste F, respectivamente.
Conforme Mendes et al. (2010), as temperaturas de 41 ou $42{ }^{\circ} \mathrm{C}$, por períodos de tempo variando entre 48 e 72 horas são as condições mais indicadas para a condução do teste de envelhecimento acelerado, para diversas espécies.

Observa-se que os testes de envelhecimento acelerado, realizados a $41{ }^{\circ} \mathrm{C} / 96 \mathrm{~h}$ e a $43^{\circ} \mathrm{C} / 48 \mathrm{~h}$, classificaram as sementes dos cinco lotes em apenas dois níveis de vigor, apontando o lote 1 como mais vigoroso. De maneira contrária, Nery et al. (2009) concluíram que o teste de envelhecimento acelerado tradicional, a $41^{\circ} \mathrm{C}$, durante 96 horas e com solução saturada, a $41^{\circ} \mathrm{C}$ por 72 horas, foi eficiente para avaliação do potencial fisiológico de sementes de nabo forrageiro. Já Ohlson et al. (2010), concluíram que o teste de envelhecimento acelerado a temperatura de $43{ }^{\circ} \mathrm{C}$, durante 48 horas, fornece informações consistentes que permitem separar os lotes de sementes de trigo em diferentes níveis de vigor.

É importante ressaltar que as sementes de crambe apresentam uma estrutura tegumentar denominada pericarpo, cuja função é proteger as sementes armazenadas por longos períodos, sem perda significativa do seu poder germinativo. No entanto, em alguns casos, a presença do pericarpo pode ocasionar elevada desuniformidade ou mesmo ausência ou redução da germinação das sementes.

Verifica-se que a exposição das sementes de crambe ao envelhecimento, a $43^{\circ} \mathrm{C}$, nos períodos de 48, 72 e 96 horas, promoveu incremento da percentagem de germinação de sementes (Tabela 4). Possivelmente, a elevação da temperatura atuou como agente escarificador, provocando a ruptura ou enfraquecimento do pericarpo, proporcionando melhores respostas na germinação das sementes, quando comparada à observada na temperatura de $41^{\circ} \mathrm{C}$. Em estudo realizado com sementes de repolho e couvebrócolis, da mesma família do crambe, Costa et al. (2008)

Tabela 4. Germinação (\%) após os períodos do teste de envelhecimento acelerado a $43^{\circ} \mathrm{C}$, em cinco lotes de sementes de crambe

\begin{tabular}{lccc}
\hline Lote & $\mathbf{4 3}^{\mathbf{0}} \mathbf{C} \mathbf{4 8 h}$ & $\mathbf{4 3}^{\circ} \mathbf{C} / \mathbf{7 2 h}$ & $\mathbf{4 3}^{\circ} \mathbf{C} / \mathbf{9 6 h}$ \\
\hline 1 & $26 \mathrm{~A}$ & $28 \mathrm{~A}$ & $35 \mathrm{~A}$ \\
2 & $9 \mathrm{~B}$ & $24 \mathrm{~A}$ & $33 \mathrm{~A}$ \\
3 & $10 \mathrm{~B}$ & $23 \mathrm{~A}$ & $42 \mathrm{~A}$ \\
4 & $5 \mathrm{~B}$ & $26 \mathrm{~A}$ & $34 \mathrm{~A}$ \\
5 & $5 \mathrm{~B}$ & $21 \mathrm{~A}$ & $34 \mathrm{~A}$ \\
\hline Média & 11 & 24 & 35 \\
\hline Teste "F" & $11,762^{* *}$ & $0,134^{\text {ns }}$ & $0,109^{\text {ns }}$ \\
\hline CV $(\%)$ & 11,3 & 22,0 & 17,6 \\
\hline
\end{tabular}

Médias com letras maiúsculas diferentes na mesma coluna diferem $(\mathrm{P}<0,05)$ pelo teste Scott-Knott.

ns - Não significativo pelo teste $\mathrm{F}$ a $5 \%$ de probabilidade.

$(*)$ e (**) Significativo a 5 e a $1 \%$ de probabilidade, pelo teste $\mathrm{F}$, respectivamente. 
verificaram que o envelhecimento acelerado a $42{ }^{\circ} \mathrm{C}$, durante os períodos de 48, 72 e 96 horas, foram eficientes em classificar os lotes em diferentes níveis de vigor.

Foi calculado o coeficiente de correlação de Pearson, entre os resultados obtidos no teste de envelhecimento acelerado e os dos demais testes, para avaliar a qualidade fisiológica inicial dos lotes (Tabela 5). Verifica-se que, para as combinações $41{ }^{\circ} \mathrm{C} / 48 \mathrm{~h}, 41^{\circ} \mathrm{C} / 72 \mathrm{~h}, 41^{\circ} \mathrm{C} / 96 \mathrm{~h}$ e $43^{\circ} \mathrm{C} /$ 72h, o coeficiente de correlação de Pearson não foi significativo com nenhuma das variáveis analisadas na qualidade inicial dos lotes. Houve correlação significativa entre a combinação $43^{\circ} \mathrm{C} / 48 \mathrm{~h}$ e os valores obtidos do teste de germinação, primeira contagem e emergência de plântulas, enquanto a combinação $43^{\circ} \mathrm{C} / 96 \mathrm{~h}$ correlacionou-se apenas com a primeira contagem de germinação.

Entretanto, pelo fato de mesmo as combinações $41^{\circ} \mathrm{C}$ por 72 e $96 \mathrm{~h}$ não terem se correlacionado com os dados obtidos na avaliação da qualidade inicial dos lotes, ressalta-se que essas combinações foram eficientes na estratificação dos lotes quanto ao vigor. Essa discrepância entre os resultados pode estar associada a uma possível dormência presente nas sementes de crambe, conforme já relatado anteriormente.

De acordo com Marcos Filho (1999a), o teste de envelhecimento acelerado é utilizado para avaliar o vigor de sementes de diversas espécies e está incluído em programas de controle de qualidade, por empresas produtoras de sementes, pois, em poucos dias, podem-se obter informações relativamente seguras sobre o potencial de armazenamento dos lotes processados e a emergência das plântulas em campo.

De maneira geral, o uso de testes de vigor na indústria de sementes é uma realidade para a maioria das grandes culturas e hortaliças de importância econômica. Apesar da grande demanda por informações sobre a cultura do crambe, em função do seu potencial econômico, os trabalhos de pesquisa encontram-se em fase inicial, especialmente na área de tecnologia de sementes.

Tabela 5. Coeficientes de correlação de Pearson (r) entre os resultados do teste de envelhecimento acelerado, para todos os tratamentos, e os valores de germinação $(\mathrm{G})$, primeira contagem (PC), emergência de plântulas (EP) e índice de velocidade de emergência (IVE), de cinco lotes de sementes de crambe, cultivar FMS Brilhante

\begin{tabular}{lrrrrrr}
\hline \multirow{2}{*}{ Testes } & \multicolumn{5}{c}{ Envelhecimento acelerado } \\
\cline { 2 - 7 } & $\mathbf{4 1}^{\mathbf{0}} \mathbf{C} / \mathbf{4 8 h}$ & $\mathbf{4 1}^{\mathbf{0}} \mathbf{C} / \mathbf{7 2} \mathbf{h}$ & $\mathbf{4 1}^{\mathbf{}} \mathbf{C} / \mathbf{9 6 h}$ & $\mathbf{4 3}^{\mathbf{}} \mathbf{C} / \mathbf{4 8 h}$ & $\mathbf{4 3}^{\mathbf{0}} \mathbf{C} / \mathbf{7 2} \mathbf{h}$ & $\mathbf{4 3}^{\mathbf{0}} \mathbf{C} / \mathbf{9 6 h}$ \\
\hline $\mathrm{G}$ & $0,17^{\text {ns }}$ & $0,13^{\text {ns }}$ & $0,03^{\text {ns }}$ & $0,40^{*}$ & $0,25^{\text {ns }}$ & $0,25^{\text {ns }}$ \\
PC & $0,25^{\text {ns }}$ & $0,16^{\text {ns }}$ & $0,16^{\text {ns }}$ & $0,48^{*}$ & $0,04^{\text {ns }}$ & $0,50^{*}$ \\
$\mathrm{EP}$ & $-0,30^{\text {ns }}$ & $0,07^{\text {ns }}$ & $-0,06^{\text {ns }}$ & $-0,45^{\text {ns }}$ & $-0,02^{\text {ns }}$ & $-0,19^{\text {ns }}$ \\
IVE & $-0,08^{\text {ns }}$ & $-0,01^{\text {ns }}$ & $-0,11^{\text {ns }}$ & $-0,02^{\text {ns }}$ & $0,01^{\text {ns }}$ & $-0,11^{\text {ns }}$ \\
\hline
\end{tabular}

ns - Não significativo; (*) Significativo a $5 \%$ de probabilidade pelo teste t.

\section{CONCLUSÕES}

O teste de envelhecimento acelerado, na condição de $41^{\circ} \mathrm{C}$, por $72 \mathrm{~h}$, proporciona uma maior diferenciação do vigor entre os lotes de sementes de crambe, cultivar FMS Brilhante.

\section{AGRADECIMENTOS}

Os autores agradecem à Fapemig, pelo suporte financeiro; à Unimontes, pelo apoio técnico e à COOAPI, por ceder as sementes para a realização da pesquisa.

\section{REFERÊNCIAS}

AOSA - Association of Official Seed Analysts (1983) Seed vigor testing handbook. East Lansing, AOSA. 88p. (Contribuition, 32).

Ávila PFV, Villela FA \& Ávila MSV (2006) Teste de envelhecimento acelerado para avaliação do potencial fisiológico de sementes de rabanete. Revista Brasileira de Sementes, 28:52-58.

Bittencourt SR \& Vieira RD (2006) Temperatura e período de exposição de sementes de milho no teste de envelhecimento acelerado. Revista Brasileira de Sementes, 28:161-168.
Brasil (2009) Regras para análise de sementes. Ministério da Agricultura, Pecuária e Abastecimento. Secretaria de Defesa Agropecuária. Brasília, SNAD/DNDV/CLAV. 395p.

Carneiro SMTPG, Romano E, Marianowski T, Oliveira JP, Garbim THS \& Araújo PM (2009) Ocorrência de Alternaria brassicicola em crambe (Crambe abysinica) no estado do Paraná. Summa Phytopathologica, 35:154.

Castro RD, Bradford KJ \& Hilhorst HWM (2004) Embebição e reativação do metabolismo. In: Ferreira AG \& Borghetti F (Eds.) Germinação: do básico ao aplicado. Porto Alegre, Artmed. p.149162.

Coimbra RA, Martins CC, Tomaz CA \& Nakagawa J (2009) Testes de vigor utilizados na avaliação da qualidade fisiológica de sementes de milho-doce (sh2). Ciência Rural, 39:2402-2408.

Costa CJ, Trzeciak MB \& Villela FA (2008) Potencial fisiológico de sementes de brássicas com ênfase no teste de envelhecimento acelerado. Horticultura Brasileira, 26:144-148.

Delouche JC \& Baskin CC (1973) Accelerated aging techniques for predicting the relative storability of seed lots. Seed Science and Technology, 1:427-452.

Dutra AS \& Vieira RD (2004) Envelhecimento acelerado como teste de vigor para sementes de milho e soja. Ciência Rural, 34:715-721.

Rev. Ceres, Viçosa, v. 61, n.2, p. 202-208, mar/abr, 2014 
Flavio JJP \& Paula RC (2010) Testes de envelhecimento acelerado e de condutividade elétrica em sementes de Dictyoloma vandellianum A. Juss. Scientia Forestalis, 38:391-399.

Freitas RA \& Nascimento WM (2006) Teste de envelhecimento acelerado em sementes de lentilha. Revista Brasileira de Sementes, 28:59-63.

Jasper SP, Biaggioni MAM, Silva PRA, Seki AS \& Bueno OC (2010) Análise Energética da cultura do crambe (Crambe abyssinica hochst) produzida em plantio direto. Engenharia Agrícola, 30:395-403.

Maguire JA (1962) Speed of germination: aid in selection an evaluation for seedling emergence and vigor. Crop Science, $2: 176-177$

Marcos Filho J (1999a) Teste de envelhecimento acelerado. In Krzyzanowski FC, Vieira RD \& França Neto JB (Eds.) Vigor de sementes: conceitos e testes. Londrina, ABRATES. p.01-24.

Marcos Filho J (1999b) Testes de vigor: importância e utilização In: Krzyzanowski FC, Vieira RD \& França Neto JB (Eds.) Vigor de sementes: conceitos e testes. Londrina: ABRATES. p.01-21.
Mendes RC, Dias DCFS, Pereira MD \& Dias LAS (2010) Testes de vigor para avaliação do potencial fisiológico de sementes de mamona (Ricinus communis L.). Ciência e Agrotecnologia, 34:114-120.

Nery MC, Carvalho MLM \& Guimarães RM (2009) Testes de vigor para avaliação da qualidade de sementes de nabo forrageiro. Informativo ABRATES, 19:09-20.

Ohlson OC, Krzyzanowski FC, Caieiro JT \& Panobianco M (2010) Teste de envelhecimento acelerado em sementes trigo. Revista Brasileira de Sementes, 32:118-124.

Pitol C (2008) Cultura do Crambe. In: Tecnologia e Produção: Milho Safrinha e Culturas de Inverno. Maracajú, Fundação MS. p.85-88.

Rocha MS, Braga Junior JM, Bruno RLA, Viana JS, Moura MF, Beltrão NEM \& Guedes RS (2007) Teste de envelhecimento acelerado em sementes de mamona cultivar BRS Energia. In: $4^{\circ}$ Congresso Brasileiro de Plantas Oleaginosas, Óleos, Gorduras e Biodiesel, Varginha. Anais, Universidade Federal de Lavras. p.1421-1431. 